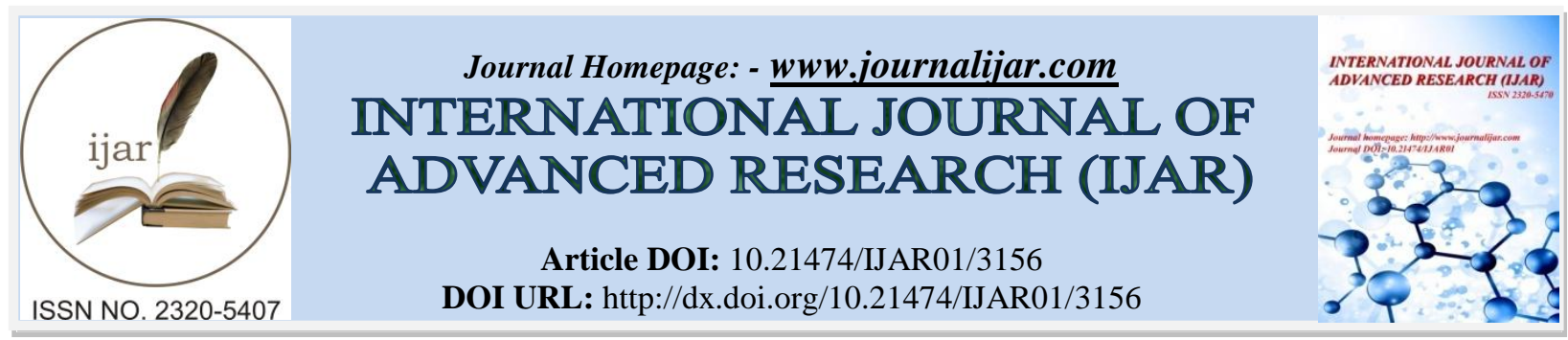

RESEARCH ARTICLE

\title{
EQUILIBRIUM ISOTHERM, KINETIC AND THERMODYNAMIC STUDIES OF THE ADSORPTION OF CONGO RED DYE ONTO ACTIVATED CARBON FROM SNAIL SHELL.
}

Ikhazuangbe P. M. $\mathrm{O}^{1}$ and Eruoto M.O ${ }^{2}$.

1. Federal University of Technology, Chemical engineering department, Owerri, Nigeria.

2. Western Delta University, Physics with electronics department, Oghara, Nigeria.

\section{Manuscript Info}

Manuscript History

Received: 18 December 2016

Final Accepted: 16 January 2017

Published: February 2017

Key words:-

Snail shell, adsorption isotherm, kinetic, thermodynamic, Congo red.

\begin{abstract}
Snail shell samples were washed and carbonized at $400^{\circ} \mathrm{C}$, ground, sieved and activated with $0.1 \mathrm{M} \mathrm{HCl}$ at $800^{\circ} \mathrm{C}$ in a furnace. The activated carbon prepared, were used as adsorbent to remove Congo red from aqueous solution. Factors such as contact time, temperature and initial concentration were studied through single-factor experiment, while other factors are kept constant (at $30 \mathrm{~min}, 30^{\circ} \mathrm{C}$ and $50 \mathrm{mg} / \mathrm{L}$ ) in each. Adsorption isotherm, kinetic and thermodynamic studies were carried out for the corresponding experiment. The isotherm results show that, Freundlich isotherm has the best fit for the adsorption. Again, the adsorption kinetic followed pseudo-second order reaction with rate constant $\left(\mathrm{K}_{2}\right)=0.2667 \mathrm{~g} / \mathrm{mg} \cdot \mathrm{min}$, correlation coefficient, $\left(\mathrm{R}^{2}\right)$ $=0.9999$ and adsorption capacity, $\left(\mathrm{q}_{\mathrm{e}}\right)=2.2573 \mathrm{mg} / \mathrm{g}$. Also, the thermodynamic parameters, enthalpy $(\Delta \mathrm{H})=23.93 \mathrm{KJ} / \mathrm{mol}$, entropy $(\Delta \mathrm{S})=84.64 \mathrm{~J} / \mathrm{mol} . \mathrm{K}$ and negative values of free energy $(\Delta G)$ were obtained. These results show that activated carbon from snail shell is a good low-cost adsorbent for the removal of Congo red from aqueous solution.
\end{abstract}

\section{Introduction:-}

Dye removal from wastewater is the main problem encountered in the industries where they are used. Color is a visible pollutant and the presence of even very minute amount of coloring substance makes it undesirable due to its appearance. Therefore, it is required that the color-bearing effluents be treated to remove the color/dye in an economical fashion to the prescribed concentration level before they are discharged into bodies of water. All methods used for the removal suffer from one or other limitations, and none of them were successful in completely removing the color from wastewater. Adsorption process is efficient for removal of colors, odor, organic and inorganic pollutants from the industrial wastewater. Currently, the most commonly used adsorption agent in industry is activated carbon, which was successfully tested also for the removal of dye from wastewater. Although commercial activated carbon is a preferred adsorbent for color removal, its widespread use is restricted due to high cost, and its regeneration and reuse makes it more costly. Therefore, a number of nonconventional adsorbents have been tried for the treatment of wastewaters. Natural materials, biosorbents, and waste materials from industry and agriculture represent potentially more economical alternative adsorbents (Emrah et al, 2008). 
In this study, the ability of snail shell carbon to remove Congo red by adsorption is been studied. The Langmuir, Freundlich, Redlich-Peterson, Dubinin-Radushkevic and Temkin isotherms will be used to fit the equilibrium data. The order of the adsorption and the thermodyanmic paramenters will also be determined (Hakan, İlknur, \& Belgin, 2008).

\section{Materials and Methods:- \\ Preparation of adsorbents:-}

Samples of snail shell were picked from the environment in Elele, Rivers State, Nigeria. The snail shells were washed with tap water until the washing water was colorless. They were respectively dried in the open air. The dried snail shells were carbonized in a furnace (SX-5-12) at $400^{\circ} \mathrm{C}$ for 3 hours and the charred snail shells were allowed to cool to room temperature, ground and sieved $(200-600 \mu \mathrm{m})$. It was chemically activated by weighing $100 \mathrm{gram}$ of the ground carbonized snail shells in $300 \mathrm{ml}$ of $0.1 \mathrm{M} \mathrm{HCl}$ solution, mixed and heated until it formed slurry. The slurry was heated in a furnace $(\mathrm{SX}-5-12)$ at $800^{\circ} \mathrm{C}$ for 3 hours, cooled, washed with de-ionized water and dried in an oven at $110^{\circ} \mathrm{C}$ for 2 hours (Gumus and Okpeku, 2015).

\section{Preparation of adsorbate:-}

The Congo red used, is of laboratory grade (KEM LIGHT, India). The solution was prepared with de-ionized water from Ion-exchange (Indian) Ltd, Eleme, Port Harcourt, Nigeria. 150mg of the dye was weighed and dissolved in 1 liter of de-ionized water to prepare the standard solution.

\section{Adsorption experiment:-}

$1000 \mathrm{mg}$ of the activated carbon from snail shell was mixed with 50ml of Congo red solution $(25,50,75,100,125$ and $150 \mathrm{mg} / \mathrm{L}$ ) at $30^{\circ} \mathrm{C}$ in a temperature controlled water bath with constant shaking. The samples were withdrawn after 30 minutes and dye solutions were separated from the adsorbent using Whatmann filter paper. The concentration of the filtrate was measured with a UV spectrophotometer (2OD) at 496nm. The experiment was repeated using $1000 \mathrm{mg}$ of the activated carbon with $50 \mathrm{ml}$ of $50 \mathrm{mg} / \mathrm{L}$ concentration of Congo red solution at $30^{\circ} \mathrm{C}$. The samples were withdrawn after 30,60, 90,120, 150 and 180minutes respectively. Again 1000mg of the activated carbon mixed with $50 \mathrm{ml}$ of $50 \mathrm{mg} / \mathrm{L}$ concentration of Congo red solution at $30,35,40,45,50$ and $55^{\circ} \mathrm{C}$ in a temperature controlled water bath (DK - 420) with constant shaking was also carried out. The samples were withdrawn after 30minutes respectively.

The adsorption capacity of Congo red dye adsorbed onto the snail shell adsorbent at equilibrium was calculated with the following equation:

$q_{e}=\frac{\left(C_{o}-C_{e}\right) V}{X}$

Where $\mathrm{C}_{0}(\mathrm{mg} / \mathrm{L})$ and $\mathrm{C}_{\mathrm{e}}(\mathrm{mg} / \mathrm{L})$ are the initial and equilibrium concentration of the dyes, V (L) is the volume of solution, $\mathrm{X}(\mathrm{g})$ is the weight of adsorbent in one container.

\section{Theory:-}

\section{Langmuir adsorption isotherm (model) :-}

The Langmuir equation is probably the best known and most widely applied adsorption isotherm. It is represented as follows in equation 3

$q_{e}=\frac{a b C_{e}}{1+a C_{e}}$

Rearranging equation 2, makes the equation linearized from which values of a and $b$ can be determined from the slope and intercept respectively of the plot of $C e / q e$ versus $\mathrm{C}_{\mathrm{e}}$

$\frac{C e}{q e}=\frac{1}{b Q o}+\frac{C e}{Q o}$

Where $\mathrm{Q}_{\mathrm{o}}$ and $\mathrm{b}$ are Langmuir constants, $\mathrm{q}_{\mathrm{e}}$ is amount of solute removed or adsorbed at equilibrium. $\mathrm{C}_{\mathrm{e}}$, is equilibrium concentration of mixtures. Thus $\mathrm{Q}_{\mathrm{o}}, \mathrm{b}$ and the squared of the regression coefficient $\left(\mathrm{R}^{2}\right)$, are adsorption parameters estimated by Langmuir model, which are used to suggest whether the adsorption can be modeled by Langmuir is isotherm.

\section{Freundlich adsorption isotherm (model):-}

The Freundlich isotherm is an empirical relationship which often gives a more satisfactory model of experimental data. The Freundlich model can be applied onto heterogeneous surface involving multilayer adsorption. It can be expressed as follows: 
$\mathrm{K}_{\mathrm{f}} C_{e}^{1 / n}$

4

However, the linearized Freundlich adsorption isotherm can be expressed in the form;

$\log q_{e}=\log \left(\mathrm{K}_{\mathrm{f}}\right)+\frac{1}{n} \log \mathrm{C}_{\mathrm{e}}$

Where $\mathrm{C}_{\mathrm{e}}$ and $\mathrm{q}_{\mathrm{e}}$ are equilibrium concentration and amount of congo red adsorbed at equilibrium stage, while $\mathrm{K}_{\mathrm{f}}$ and $\mathrm{n}$ are Freundlich constants which incorporates all factors affecting the adsorption process (adsorption capacity and intensity).

\section{Redlich-Peterson isotherm (model) :-}

The Redlich-Peterson (R-P) isotherm model can be represented as $q_{e}=\frac{K_{R} C_{e}}{1+a_{R} C_{R}^{\beta}}$

Where $\mathrm{K}_{\mathrm{R}}$ is the R-P isotherm constant $(1 / \mathrm{mg})$, $\mathrm{a}_{\mathrm{R}}$ is also a constant $\left(\frac{1}{m g}\right)^{\frac{1}{\beta}}$ and $\beta$ is the exponent which lies between 0 and 1. The R-P isotherm has a linear dependence on concentration in the numerator and an exponential function in the denominator. It approaches the Freundlich model at high concentrations and is in accord with the low concentration limit of the Langmuir equation.

\section{Adsorption kinetics:-}

The pseudo first order and second order kinetic models were tested at different concentrations in this study to determine which model is in good agreement with experiment $\mathrm{q}_{\mathrm{e}}$ (adsorption capacity) value, thus suggesting which model the adsorption system follows.

\section{Pseudo- first order equation:-}

The Largergren model, proposed in 1898, assumes a first order adsorption kinetics and can be represented by the equation.

$\frac{d q_{t}}{d t}=\mathrm{K}_{1}\left(q_{e}-q_{t}\right)$

Where $\mathrm{q}_{\mathrm{e}}$ and $\mathrm{q}_{\mathrm{t}}$ are adsorption capacity at equilibrium and at time $\mathrm{t}$, respectively $(\mathrm{mg} / \mathrm{g}), \mathrm{K}_{1}$ is the rate constant of pseudo first order adsorption $\left(\mathrm{min}^{-1}\right)$. After integration and applying boundary conditions $t=0$ to $t=t$ and $q_{t}=0$ to $q_{t}$ $=\mathrm{q}_{\mathrm{e}}$, the integrated form becomes:

$\log \left(\mathrm{q}_{\mathrm{e}}-\mathrm{q}_{\mathrm{t}}\right)=\log \left(\mathrm{q}_{\mathrm{e}}\right)-\frac{K_{1}}{2.303} \mathrm{t}$

The values of $\log \left(q_{e}-q_{t}\right)$ were linearly correlated with $t$. The plot of $\log \left(q_{e}-q_{t}\right)$ versus $t$ should give a linear relationship from which $\mathrm{K}_{1}$ and $\mathrm{q}_{\mathrm{e}}$ can be determined from the slope and intercept of the plot, respectively.

The pseudo second-order equation:-

The pseudo-second-order adsorption kinetic rates equation is expressed as

$\frac{d q_{t}}{d t}=\mathrm{K}_{2}\left(q_{e}-q_{t}\right)^{2}$

Applying boundary conditions, the integrated form of the equation becomes.

$\frac{t}{q_{t}}=\frac{1}{K_{2} q_{e}^{2}}+\frac{1}{q_{e}} \mathrm{t}$

The plot of $\left(\mathrm{t} / \mathrm{q}_{\mathrm{t}}\right)$ and $\mathrm{t}$ of equation 10 should give a linear relationship from which $\mathrm{q}_{\mathrm{e}}$ and $\mathrm{K}_{2}$ can be determined from the slope and intercept of the plot, respectively.

\section{Thermodynamic studies:-}

The determination of the basic thermodynamic parameters: enthalpy of adsorption $\left(\Delta \mathrm{H}^{\circ}\right)$, Gibb's free energy of adsorption $\left(\Delta \mathrm{G}^{\mathrm{o}}\right)$ and entropy of adsorption $\left(\Delta \mathrm{S}^{\mathrm{o}}\right)$, is important as it allows to estimate if the process is favorable or not from thermodynamic point of view, to assess the spontaneity of the system and to ascertain whether it is exothermic or endothermic. An adsorption process is generally considered as physical if $\Delta \mathrm{H}^{\circ}<84 \mathrm{~kJ}^{\mathrm{mol}}{ }^{-1}$ and as chemical when $\Delta \mathrm{H} \circ$ lies between 84 and $420 \mathrm{~kJ} \mathrm{~mol}^{-1}$ (Zhang et al, 2011).

$\Delta \mathrm{G}=-\mathrm{RTInK}_{\mathrm{d}}$

$\mathrm{K}_{\mathrm{d}}=\frac{q e}{C e}$

$\operatorname{InK}_{\mathrm{d}}=\frac{\Delta S}{R}-\frac{\Delta H}{R T}$

where $K_{d}$ is the distribution coefficient for the adsorption, $\mathrm{q}_{\mathrm{e}}$ is the amount of dye (mg) adsorbed on the adsorbent per $\mathrm{L}$ of solution at equilibrium, $\mathrm{C}_{\mathrm{e}}$ is the equilibrium concentration $(\mathrm{mg} / \mathrm{L})$ of the dye in solution, $\mathrm{T}$ is the absolute 
temperature, $\mathrm{R}$ is gas constant, $\Delta G^{o}, \Delta H^{o}$, and $\Delta S^{o}$ are Gibbs free energy change, enthalpy change and entropy change, respectively.

\section{Result :-}

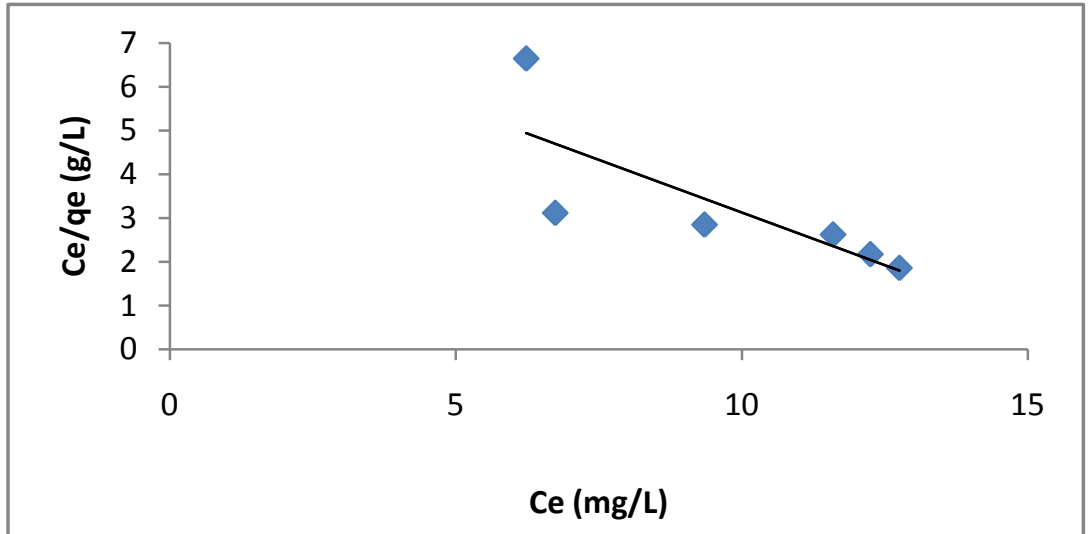

Fig. 1: Langmuir model

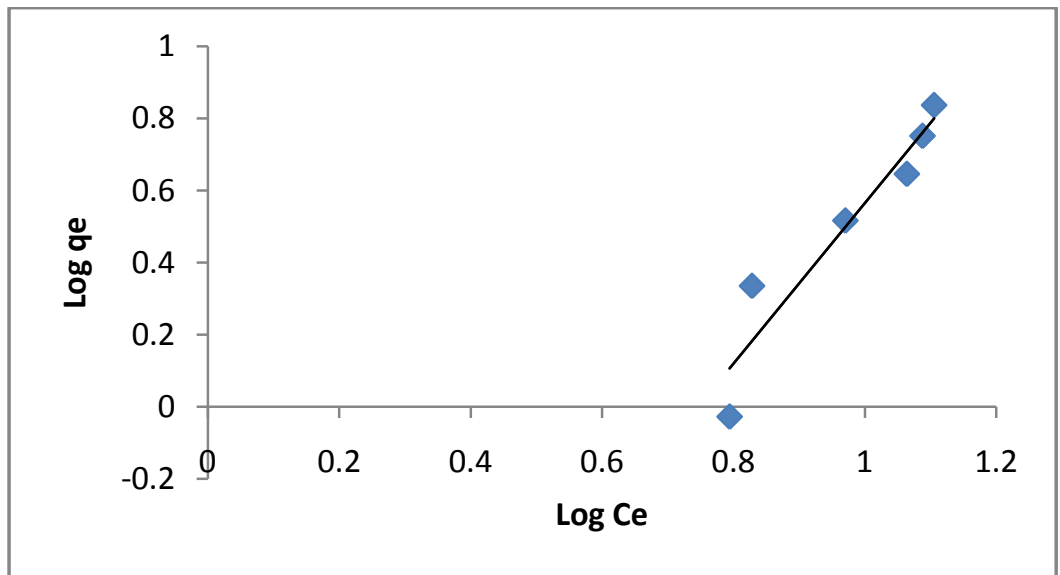

Fig. 2: Freundlich model

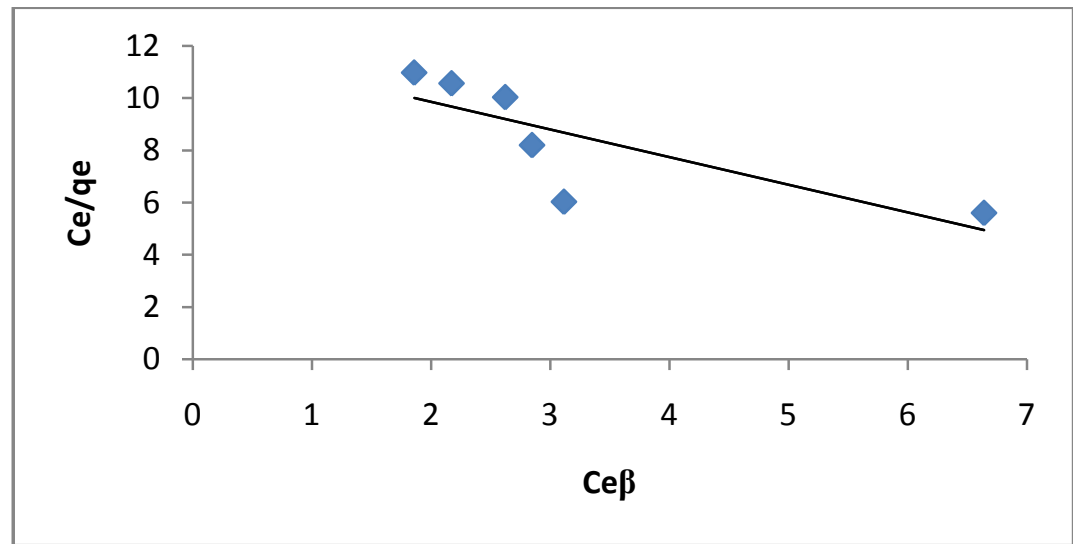

Fig. 3: Redlich-Peterson model 


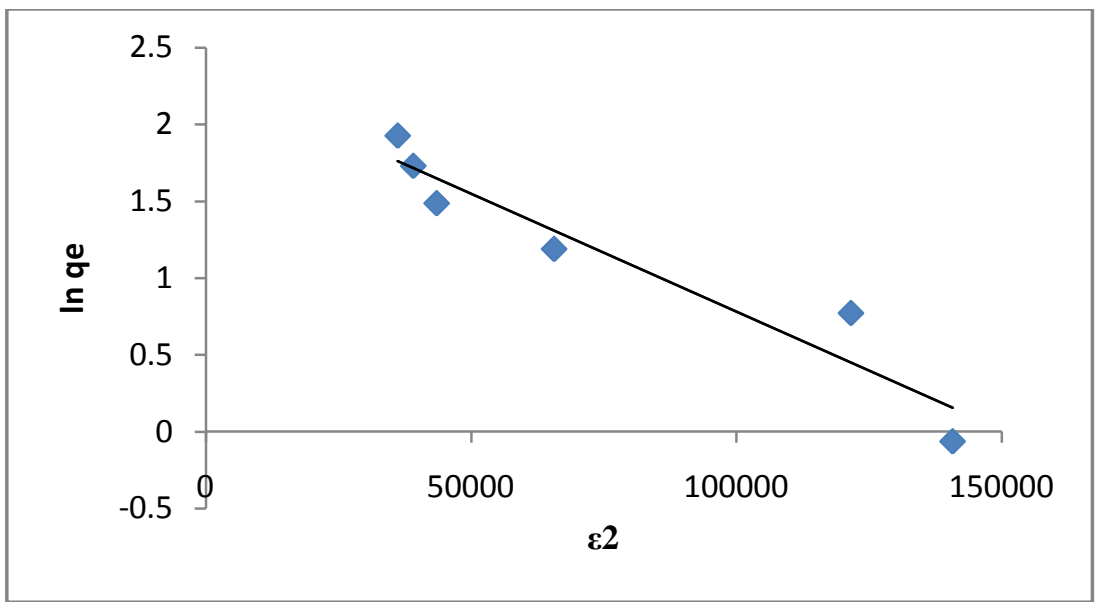

Fig. 4: Dubinin-Radushkevich model

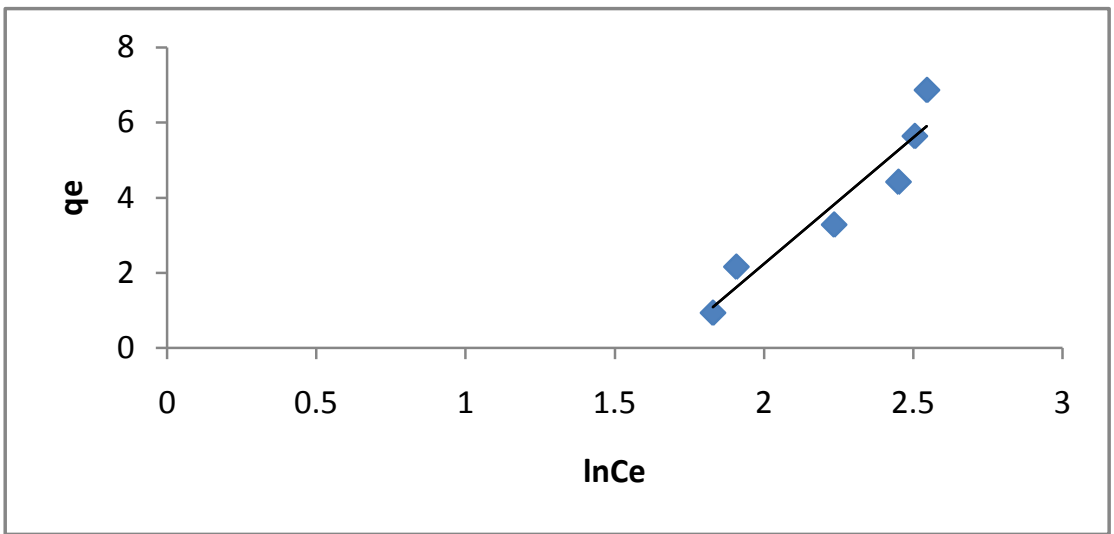

Fig. 5: Temkin model

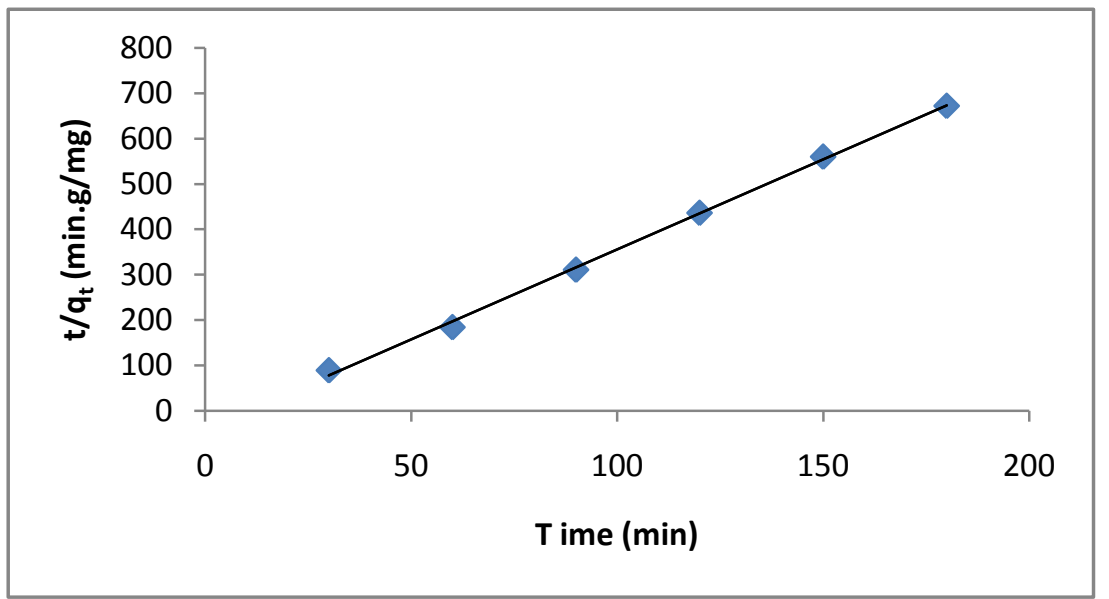

Fig. 6: Pseudo second order model 
Table 1:- Adsorption isotherm constants and kinetic for snail shell activated carbon

\begin{tabular}{|c|c|c|c|}
\hline \multicolumn{4}{|c|}{ Langmuir } \\
\hline $\mathrm{Q}_{\mathrm{o}}(\mathrm{mg} / \mathrm{g})$ & \multicolumn{2}{|l|}{$\mathrm{b}(\mathrm{L} / \mathrm{mg})$} & $\mathrm{R}^{2}$ \\
\hline-2.079 & \multicolumn{2}{|l|}{0.0606} & 0.615 \\
\hline \multicolumn{4}{|c|}{ Freundlich } \\
\hline $\mathrm{K}_{\mathrm{f}}(\mathrm{mg} / \mathrm{l})$ & \multicolumn{2}{|l|}{$\mathrm{n}(\mathrm{l} / \mathrm{g})$} & $\mathrm{R}^{2}$ \\
\hline 0.0217 & \multicolumn{2}{|l|}{0.4488} & 0.906 \\
\hline \multicolumn{4}{|c|}{ Redlich-Peterson } \\
\hline $\mathrm{K}_{\mathrm{R}}(\mathrm{L} / \mathrm{mg})$ & $\mathrm{a}_{\mathrm{R}}(\mathrm{L} / \mathrm{mg})$ & $\mathrm{R} 2$ & $\beta$ \\
\hline 0.0837 & -0.0884 & 0.617 & 0.914 \\
\hline \multicolumn{4}{|c|}{ Temkin } \\
\hline $\mathrm{b}(\mathrm{J} . \mathrm{mol}, \mathrm{l})$ & \multicolumn{2}{|l|}{$\mathrm{A}(\mathrm{L} / \mathrm{g})$} & $\mathrm{R}^{2}$ \\
\hline 374.71 & \multicolumn{2}{|l|}{0.9705} & 0.907 \\
\hline \multicolumn{4}{|c|}{ Dubinin-Radushkevic } \\
\hline $\mathrm{q}_{\mathrm{m}}(\mathrm{mg} / \mathrm{g})$ & $\mathrm{E}$ & $\mathrm{R}^{2}$ & $\beta$ \\
\hline 10.1452 & 158.1 & 0.917 & $2 \mathrm{E}-5$ \\
\hline \multicolumn{4}{|c|}{$2^{\text {nd }}$ order reaction kinetic } \\
\hline $\mathrm{K}_{2}$ (g/mg.min) & \multicolumn{2}{|c|}{$\mathrm{q}_{\mathrm{e}}(\mathrm{mg} / \mathrm{g})$} & $\mathrm{R}^{2}$ \\
\hline 0.2667 & \multicolumn{2}{|l|}{2.2573} & 0.9999 \\
\hline
\end{tabular}

Table 2:- energy parameters for Congo red adsorption by activated carbon

\begin{tabular}{|l|l|l|l|}
\hline Temperature $(\mathrm{K})$ & $\Delta G(\mathrm{KJ} / \mathrm{mol})$ & $\Delta \mathrm{H}(\mathrm{KJ} / \mathrm{mol})$ & $\Delta \mathrm{S}(\mathrm{J} / \mathrm{mol} . \mathrm{K})$ \\
\hline 303 & -4.68 & \multirow{3}{*}{23.93} & \\
\cline { 1 - 2 } 308 & -4.96 & & \\
\cline { 1 - 2 } 313 & -5.91 & & \\
\cline { 1 - 2 } 323 & -6.08 & & \\
\cline { 1 - 2 } 328 & -6.31 & & \\
\hline
\end{tabular}

\section{Discussion:-}

The values of the adsorption model are presented in table 1, showing that the correlation coefficient of Freundlich isotherm is closer to 1 than that of Langmuir, indicating that it a heterogeneous adsorption process. This is also confirmed by the value of Temkin isotherm. While Dubinin-Radushkevic isotherm value showing that the adsorption is dominated by particle diffusion.

The kinetic of adsorption of Congo red onto snail shell was studied by using pseudo first- and second-order equations, for the examined system. The pseudo second-order kinetic model provided the best correlation of the experimental data.

The positive value of $\Delta \mathrm{H}$ indicates that the adsorption of Congo red on snail shell is an endothermic and a physical process. The positive value of $\Delta \mathrm{S}$ shows the existence of structural changes at the solid-liquid interface and $\Delta \mathrm{S}$ favors ion exchange and stability of adsorption.

\section{Conclusion:-}

The adsorption of Congo red onto snail shell based-activated carbon was investigated in this research work and the results of the study indicates that snail shell will be an excellent low-cost adsorbent for the removal of Congo red dye from industrial effluents. 


\section{Reference:-}

1. Emrah, B. Mahmut, O. and Ayhan, S.I. (2008): Adsorption of malachite green onto bentonite: Equilibrium and kinetic studies and process design. Microporous and Mesoporous materials, 115:234-246

2. Gumus, R. H and Okpeku I (2015): Production of Activated Carbon and Characterization from Snail Shell Waste (Helix pomatia). Advances in Chemical Engineering and Science, 5: 51-61.

3. Hakan, D. İlknur, D. and Belgin, K. (2008): Adsorption of Textile Dye onto Activated Carbon Prepared from Industrial. J. Int. Environmental Application \& Science. 3: 381 - 389

4. Zhang, Z. Moghaddam, L. O'Hara, I.M.O. and Doherty, W.O.S. (2011): Congo red adsorption by ball-milled sugarcane bagasse. Chem. Eng. J, 178:122- 128. 